\title{
Morfologi dan Sekuensing DNA Myxobolus koi yang Menginfeksi Ikan Koi (Cyprinus carpio) di Kabupaten Blitar
}

\section{Morphology and Sequencing of Myxobolus koi DNA that Infects Koi fish (Cyprinus carpio) in Blitar Regency}

\author{
Soelistyoadi, R.N ${ }^{1 *}$, A.D. Nurekawati ${ }^{1}$, D. Setyawati ${ }^{2}$ \\ 1 Staf Fungsional Balai Karantina Ikan Pengendalian Mutu dan Keamanan Hasil Perikanan \\ Surabaya I \\ 2 Staf Fungsional Balai Karantina Ikan Pengendalian Mutu dan Keamanan Hasil Perikanan \\ Surabaya II \\ Jl. Raya Bandara Ir. H. Juanda No. 23 Sidoarjo 61254, Indonesia \\ *Email: rachmatns96@gmail.com
}

Received : 26 March 2020

Accepted : 24 April 2020

Publish : 31 April 2020

\begin{abstract}
Abstrak
Myxobolus koi adalah jenis parasit myxospore yang banyak menginfeksi ikan hias tawar, penyakit ini disebut juga myxobolusis. Saat ini terdapat 29 spesies Myxobolus yang telah teridentifikasi menginfeksi Cyprinus carpio, dengan 17 diantaranya menginfeksi insang, sehingga akan sulit menentukan jenis spesies Myxobolus dengan cara konvensional. Penelitian ini bertujuan untuk mengidentifikasi spesies Myxobolus yang menginfeksi ikan koi Cyprinus carpio berdasarkan analisa konvensional dan secara molekuler. Spora Myxobolus yang diperoleh dari Kabupaten Blitar secara mikroskopis memiliki ukuran panjang spora 11-14 $\mu \mathrm{m}$ dengan rata-rata $12,82 \pm 0,75 \mu \mathrm{m}$ dan lebar 7-8 $\mu \mathrm{m}$ dengan rata-rata 7,09 $\pm 0,84 \mu \mathrm{m}$, sedangkan ukuran kapsul memiliki panjang 7-8 $\mu \mathrm{m}$ dengan rata-rata 7,36 $\pm 0,497 \mu \mathrm{m}$ dan lebar 2-3 $\mu \mathrm{m}$ dengan rata-rata $2,64 \pm 0,49 \mu \mathrm{m} \mathrm{n}=10$. Hasil elektroforesis ikan yang secara klinis terinfeksi Myxobolus koi muncul pita (band) pada $2000 \mathrm{bp}$, sequensing DNA parasit Myxobolus koi yang menginfeksi ikan koi (Cyprinus carpio) di Blitar memiliki kemiripan (percent identity) tertinggi dengan kode sampel KT.240127.1 yaitu pada Myxobolus koi yang menginfeksi ikan Rainbow trout (Oncorhynchus mykiss) di Barat Daya China. Jarak genetik sampel Myxobolus koi blitar terdekat pada sampel Myxobolus koi pada ikan koi (Cyprinus carpio) dengan kode sampel FJ841887.1 dan Myxobolus koi pada ikan rainbow trout (Oncorhynchus mykiss) dengan kode sampel KT240127.1. pada nilai yang sama 0,273 .
\end{abstract}

Keyword : Myxobolus koi, koi (Cyprinus carpio), PCR, Sekuensing.

\section{Abstract}

Myxobolus koi is a type of myxospore parasite that infects many fresh ornamental fish, this disease is also called myxobolusis. Currently there are 29 species of Myxobolus that have been identified to infect Cyprinus carpio, with 17 of them infecting gills, so it will be difficult to determine the type of Myxobolusis. This study aims to identify Myxobolus species that infect Cyprinus carpio koi fish based on conventional and molecular analysis. Myxobolus spores obtained from Blitar Regency microscopically have spores length of 11-14 $\mu \mathrm{m}$ with an average of $12.82 \pm 0.75 \mu \mathrm{m}$ and width of $7-8 \mu \mathrm{m}$ with an average of $7.09 \pm 0.84 \mu \mathrm{m}$, while the size capsules have a length of 7-8 $\mu \mathrm{m}$ with an average of $7.36 \pm 0.497 \mu \mathrm{m}$ and a width of $2-3 \mu \mathrm{m}$ with an average of $2.64 \pm 0.49 \mu \mathrm{m} \mathrm{n}=10$. Electrophoresis results of clinically infected fish Myxobolus koi appeared band (band) at $2000 \mathrm{bp}$, sequencing DNA Myxobolus koi parasites that infect koi fish (Cyprinus carpio) in Blitar have the highest similarity (percent identity) with the sample code KT.240127.1, namely on Myxobolus koi which infects Rainbow trout (Oncorhynchus mykiss) in Southwest China. The closest genetic distance of the Myxobolus koi blitar sample to the Myxobolus koi sample in koi fish (Cyprinus carpio) with sample code FJ841887.1 and Myxobolus koi in rainbow trout (Oncorhynchus mykiss) with sample code KT240127.1. at the same value 0.273 .

Keyword : Myxobolus koi, koi (Cyprinus carpio), PCR, Sequencing. 


\section{PENDAHULUAN}

Industri perdagangan ikan hias secara tidak langsung telah memindahkan jutaan ikan setiap tahun di seluruh dunia dan secara tidak langsung juga akan memindahkan penyakit dari satu area ke area yang lainnya termasuk diantaranya parasit myxosporean yang menyebabkan kematian pada ikan (Mathews et al., 2018). Data dari Kementerian Koordinator Bidang Kemaritiman pada tahun 2015 menduduki posisi lima dengan nilai ekspor US\$ 14,16 juta. Tahun 2017 nilai ekspor ikan hias Indonesia mencapai US\$ 27,61 Juta dan merupakan nilai ekspor ikan hias tertinggi dalam enam tahun terakhir (Anonymous, 2018).

Myxobolus koi adalah jenis parasit myxospore yang banyak menginfeksi ikan hias tawar, penyakit ini disebut juga myxobolusis. (Yokohama et al.,1997). Parasit Myxobolus sp. dapat merusak jaringan insang ikan, otot, usus, ginjal, dan hati (Camus dan Griffin, 2010). Ikan yang terinfeksi Myxobolus akan kesulitan untuk bernafas karena ditemukan nodul atau kista pada filament insang (Mahasri, G. 2017). Seringkali infeksi parasit tidak terlihat secara visual jika tidak ada tanda-tanda khusus pada ikan, pemeriksaan dapat dilakukan dengan membuat preparat rentang (smear) atau dengan melakukan pemeriksaan yang didasarkan pada gejalagejala fisik yang meliputi perubahan tingkah laku, lesi-lesi tubuh, perubahan morfologis dan anatomi ikan ( Sarjito et al., 2013).

Metode yang banyak dilakukan pada pengujian parasit pada ikan hias tawar adalah dengan penanda tradisional (biokimia, histologis, morfologis dan fisiologis), namun penyakit pada ikan biasanya sulit untuk dikendalikan dan disembuhkan ketika penyakit telah menginfeksi, sering terlambat dalam penanganan untuk mencegah kerugian yang lebih besar, untuk itu sangat penting untuk mengetahui tingkat kesehatan ikan (Tonguthai, 1997; Robert, R.J. 2012).

Diagnose definitif dilakukan untuk mendapatkan kepastian mengenai penyebab suatu penyakit 
antara lain dengan uji PCR, imunokimia dan imunohistokimia, hingga saat ini metode yang cepat dan sensitif adalah uji PCR, diagnosis definitif cenderung dilakukan untuk mendapatkan kepastian tentang jenis penyakit yang menyerang ikan. Myxobolus sp memilki morfologi yang mirip dengan Myxobolus toyami, Myxobolus longisporus dan Myxobolus koi (Alvin C et al., 2010). Saat ini terdapat 29 spesies Myxobolus yang telah teridentifikasi menginfeksi Cyprinus carpio, dengan 17 diantaranya menginfeksi insang, dan dalam banyak laporan menyerang spesies ikan mas dari Asia dan Eropa. (Camus dan Griffin. 2010), sehingga akan sulit menentukan jenis spesies Myxobolus dengan cara konvensional. Penelitian ini bertujuan untuk mengidentifikasi spesies Myxobolus yang menginfeksi ikan koi Cyprinus carpio berdasarkan analisa konvensional dan secara molekuler.

\section{MATERI DAN METODE}

\section{Alat dan Bahan}

Sampel Ikan Koi (Cyprinus carpio) dengan ukuran 5-7 cm, ikan yang diambil merupakan ikan dengan gejala klinis infeksi parasit Myxobolus koi seperti insang membengkak, operkulum tidak dapat menutup sempurna dan terdapat nodul pada bagian insang. Bahan yang digunakan PCR antara lain: Silica Extraction Kit (GeneReach Biotechnology Corp), Master Mix (MyTaq HS Red Mix,2x BIOLINE), ddH2O/Nuclease Free water (PCR Grade Water) (Ambion,AM9937), Agarose gel (1\% Gel O-Shooter) (LE Agarose, R9012LE-500gr), DEPC $\quad \mathrm{H}_{2} \mathrm{O} \quad$ (GeneReach Biotechnology Corp), GT Buffer (GeneReach Biotechnology Corp), Etanol 70\%, TAE Buffer, Ethidium bromide (Maestro, MR031203), SYBR Safe DNA gel strain (Invitrogen), Marker 100 bp DNA Ladder 100-3000 bp (Geneaid), Marker 100 bp DNA Ladder 100-3000 bp (Nexmark), template DNA. Primer Myxobolus ERB1 dan ERB 10, sesuai dengan Tabel 1. 
Tabel 1. Primer Myxobolus sp

\begin{tabular}{lllll}
\hline NO & PRIMER & SEQUENCE (5`3`) & DIRECTION & SIZE (bp) \\
\hline 1. & ERB1 & ACCTGGTTGATCCTGCCAG & Forward & $2-20$ \\
2. & ERB10 & CCTCCGCAGGTTCACCTACGG & Reverse & 2079-2059 \\
\hline
\end{tabular}

\section{Metode Penelitian}

\section{Metode Konvensional}

Cyste yang berwarna putih pada tubuh ikan dapat dibuat smear pada slide glass lalu dikering anginkan, selanjutnya dilakukan pewarnaan dengan larutan Lugol's iodine solution 10 - 15 menit, bilas dengan air lalu keringkan diudara. Spesimen kemudian diamati dibawah mikroskop untuk melihat bentuk spora dan polar kapsul (Lom J, Dyková I, 1992).

\section{Metode PCR (Polymerase Chain Reaction)}

\section{Ekstraksi}

DNA

diekstraksi

menggunakan (Gene) Silica

Extraction Kit dari jaringan yang diawetkan dalam larutan etanol absolut. Masing-masing sampel jaringan insang dan usus yang teridentifikasi Myxobolus maupun yang sehat dimasukkan kedalam mikrotube $1,5 \mathrm{ml}$, tambahkan dengan $900 \quad \mu \mathrm{l}$ GT Buffer, haluskan dengan menggunakan pastle penggerus, sentrifugasi pada kecepatan 12000 rpm selama 3 menit. Larutan lapisan diambil $600 \mu \mathrm{l}$ dipindahkan ke dalam dalam mikrotube 1,5 $\mathrm{ml}$ yang baru, masukkan silica $40 \mu \mathrm{l}$, vortex agar homogen dan disentrifugasi pada kecepatan 12000 rpm selama 15 detik (tidak boleh lebih dari 20 detik). Setelah di sentrifugasi buang larutannya, cuci pellet silica dengan $500 \mu \mathrm{l}$ GT Buffer, vortex sampai pellet silica membentuk suspensi, di sentrifugasi pada kecepatan 12000 rpm selama 15 detik, buang larutannya, tambahkan 1 $\mathrm{ml}$ ethanol $70 \%$ untuk mencuci pellet silica dan vortex sampai pellet silica membentuk suspensi. Sentrifugasi pada kecepatan 12.000 rpm selama 15 detik. buang etanol, gunakan mikropippet untuk mengambil ethanol yang masih tersisa, $\begin{array}{lllll}\text { tambahkan } & 1 & \mathrm{ml} & \mathrm{ddH}_{2} \mathrm{O} & \text { untuk }\end{array}$ meresuspensikan pellet silica, vortex sampai pellet silica 
membentuk suspense. Inkubasi pada suhu $55^{\circ} \mathrm{C}$ selama 10 menit, homogenkan dengan di vortex selanjutnya disentrifugasi pada kecepatan $12.000 \quad \mathrm{rpm}$ selama 2 menit, kemudian pindahkan 500 $\mu 1$ dari larutan atas ke dalam mikrotube baru dan siap digunakan (Nurekawati, A.D., 2016).

\section{Amplifikasi}

Amplifikasi bertujuan untuk memperbanyak DNA dari template, penelitian ini menggunakan Primer untuk amplifikasi merupakan primer spesifik pada 18S SSU rDNA untuk mendeteksi Myxobolus sp (Tabel 1). Pasangan primer yang digunakan untuk mendeteksi parasite Myxobolus sp adalah 1 set primer spesifik (Camus dan Griffin. 2010).

\section{Elektroforesis}

Hasil amplifikasi DNA diperiksa menggunakan $1,5 \%$ gel agarose direndam menggunakan TAE buffer 1X. Lubang pada gel diisi secara berurutan dengan marker, $8 \mu 1$ hasil amplifikasi dan blanko kontrol. Proses elektroforesis dilakukan selama 45 menit dengan voltase 100 volt. Agarose yang telah ditambahkan $\mathrm{SyBr}$ save (Invitrogen) selama 15 menit direndam dalam buffer TAE 1x. Gel diletakkan pada gel documentation, diamati di bawah sinar UV dan didokumentasikan.

\section{Sekuensing DNA}

Setelah proses amplifikasi dilanjutkan proses sekuensing untuk mengetahui susunan DNA dari parasit, Sekuensing DNA merupakan proses atau teknik penentuan urutan basa nukleotida pada suatu segmen molekul DNA, merupakan informasi paling mendasar suatu gen atau genom karena mengandung instruksi yang dibutuhkan untuk pembentukan tubuh mahluk hidup.

Hasil runutan nukleotida gen Myxobolus disesuaikan dengan database atau library yang tersimpan dalam genbank yaitu National Centre for Biotechnology Information (http://www.ncbi.nlm.nih.gov/blast) melalui program BLAST, untuk mendapatkan persentase kesamaan 
dengan data base. Sisi homolog runutan nukleotida gen DNA dari spesies yang diperoleh dan hasil penelusuran melalui progran BLAST selanjutnya disejajarkan (multiple alligment) dengan menggunakan ClustalW. Identifikasi spesimen dilakukan melalui konstruksi pohon kekerabatan dan persentase indeks kesamaan.

Analisis penanda genetik, keragaman genetik, jarak genetik dari runutan nukleotida gen parsial DNA myxobolus dilakukan mengunakan program MEGA versi 6.06 (Tamura et al., 2013; Fahmi et al., 2017).

\section{Analisis Data}

Metode penelitian yang digunakan adalah deskriptif kualitatif, yaitu metode yang berfungsi untuk mendeskripsikan atau memberi gambaran terhadap obyek yang diteliti melalui data atau sampel yang telah terkumpul (Sugiono, 2012). Data hasil sekuensing berupa runutan nukleotida gen Myxobolus dianalisa dengan database yang tersimpan dalam genbank National Centre for Biotechnology Information (http://www.ncbi.nlm.nih.gov/bla st) sehingga mendapatkan persentase kesamaan dengan data base.

\section{HASIL DAN PEMBAHASAN}

Benih ikan sampel diambil dengan ukuran 5-7 $\mathrm{cm}$ dengan berat 8-10 gram Pengambilan ikan sampel dilakukan di kolam pembesaran milik pembudidaya ikan koi yang berlokasi di Desa Kemloko dan Desa Kedungwaru Kecamatan Nglegok Kabupaten Blitar Jawa Timur. ( $8^{\circ} 02^{\prime} 04.3^{\prime \prime S}$ $\left.112^{\circ} 12^{\prime} 12.2^{\prime \prime} \mathrm{E}\right)$. Pengamatan gejala klinis dilakukan pada kolam pembesaran, ikan yang terinfeksi parasit Myxobolus akan memiliki gerakan operculum yang lebih cepat dibandingkan ikan sehat dan pada ikan yang terinfeksi berat ikan akan sering menuju permukaan air untuk bernafas (Sumuduni et al., 2018). Pada ikan yang terinfeksi terdapat nodul putih pada insang dan operculum yang tidak dapat menutup dengan sempurna serta insang akan berwarna lebih pucat.

Morfologi spora Myxobolus sp. memiliki spora berbentuk elipsoid, ovoid atau membulat yang terlihat di dalam valvula, didalam spora 
tersebut terdapat $1-4$ polar kapsul. selain polar kapsul, setiap spora juga memiliki sporoplasma, yaitu tubuh protoplasmatik, organ ini seringkali berisi vakuola yang disebut vakuola iodinophilous. (Hoffman, 1999). Dari hasil pengamatan secara konvensional Myxobolus dengan pewarnaan Lugol's iodine perbesaran 100X yang ditemukan memiliki ciriciri berbentuk pyriformis dengan posterior yang bulat, dan mempunyai dua buah polar kapsul pada bagian anterior spora (Gambar 1) dengan panjang spora $14 \mu \mathrm{m}$, lebar spora 8 $\mu \mathrm{m}$, panjang polar kapsul $8 \mu \mathrm{m}$ dan lebar polar kapsul $3 \mu \mathrm{m}$ (Gambar 2). Sedangkan hasil rata-rata pengukuran 10 sampel myxobolus dapat dilihat pada Tabel 2.
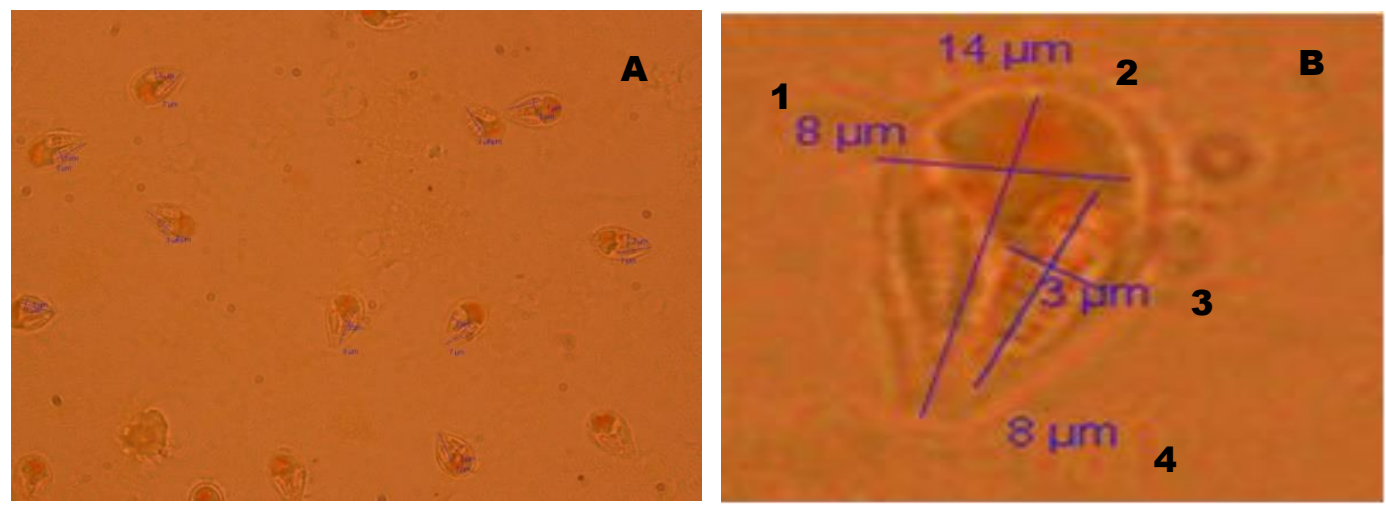

Gambar 1. (A); Spora Myxobolus sp. dengan pewarnaan Lugol's iodine perbesaran 100X (Mikroskop Olympus CX31), (B); Morfologi Spora Myxobolus sp dalam ukuran $\mu \mathrm{m}$. 1. Lebar Spora; 2. Panjang spora; 3. Lebar polar kapsul; 4. Panjang polar kapsul 
Tabel 2. Hasil Identifikasi Spora dari Sampel Ikan Koi (Cyprinus carpio) di Kabupaten Blitar

\begin{tabular}{ccc}
\hline Deskripsi & \multicolumn{2}{c}{ Ikan Koi (Cyprinus carpio) $\mathrm{n}=10$} \\
\cline { 2 - 3 } Spora & Ukuran $(\mu \mathrm{m})$ & Rata-rata \pm SD $(\mu \mathrm{m})$ \\
\cline { 2 - 3 }$-\quad$ Panjang & $11-14$ & $12,82 \pm 0,75$ \\
$-\quad$ Lebar & $7-8$ & $7,09 \pm 0,84$ \\
Polar kapsul & & \\
- Panjang & $7-8$ & $7,36 \pm 0,497$ \\
- Lebar & $2-3$ & $2,64 \pm 0,49$ \\
Lokasi organ & & Insang \\
\hline
\end{tabular}

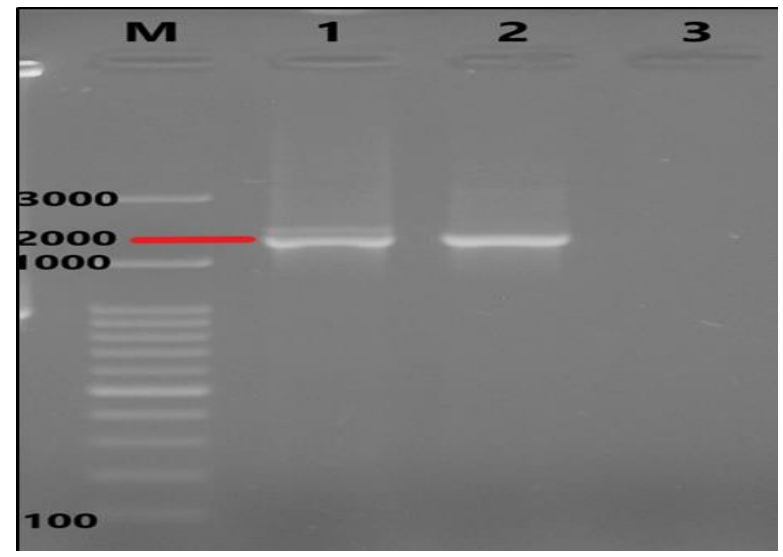

Gambar 2. Hasil elektroforesis, target band parasit Myxobolus muncul pada 2000 bp Keterangan: M= Marker;1= Kontrol positif; 2= Insang Ikan Koi positif Myxobolus; 3=Kontrol negatif

Kriteria utama dari klasifikasi Myxozoa pada awalnya adalah berdasarkan morfologi spora, namun karena memiliki keragaman pengelompokan taksonomi yang luas maka analisa nukleotida lebih efektif untuk dilakukan. Analisa nukleotida dilakukan untuk mengetahui materi genetik dari parasit, nukleotida merupakan bahan baku utama penyusun materi genetik tersusun atas basa nitrogen, gula pentosa (keduanya disebut nukleosida) dan ester fosfat, terdapat empat jenis nukleotida utama yang menyusun DNA mahluk hidup yaitu : Adenin (A), Guanin G), Timin (T) dan Sitosin (C) (Toha et al., 2016).

Sekuensing DNA selanjutnya dapat dimanfaatkan untuk menentukan identitas maupun fungsi gen atau fragmen DNA dengan cara membandingkan sekuens-nya dengan sekuens DNA lain yang sudah diketahui (Robert, 2012; Fiala et al., 2015; Lokapirnasari et al., 2017). Setelah mendapatkan hasil urutan asam basa dari sampel Myxobolus 
Blitar kemudian dilakukan

Tabel 3. Hasil Alignment dengan Myxobolus yang lain

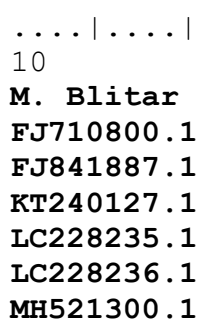

2

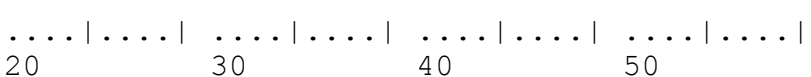

GAgACtgCGg ACGgCtCAgt AtAtCAgtgA ttAttgtttg Attgtctiac

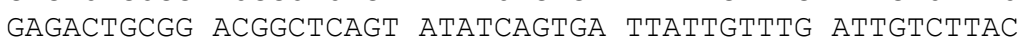
GAGACTGCGG ACGGCTCAGT ATATCAGTGA TTATTGTTTG ATTGTCTTAC GAGACTGCGG ACGGCTCAgT ATATCAgTGA tTATTGTTTG ATTGTCTTAC GAGACTGCGG ACGGCTCAgT ATATCAgTGA tTATTGTTTG ATTGTCTTAC

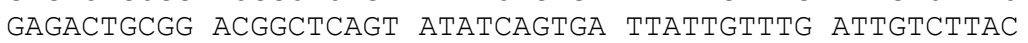
GAgACtgCGg AAggCtCAgt AtAtCAgtgA tTAttgtttg AttgtctaAC

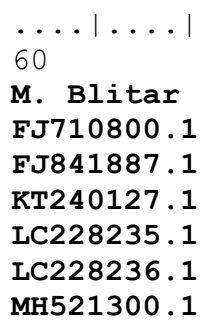

CCAtTgGAtA ACCGTGgGAA AtCtAgAgCT AAtACATGCA GTtTAtTGgC CCATTGGATA ACCGTGgGAA ATCTAGAgCT AAtACATGCA GTTTATTGgC CCATTGGATA ACCGTGgGAA ATCTAGAgCT AATACATGCA GTTTATTGgC CCATTGgATA ACCGTGGGAA ATCTAGAgCT AATACATGCA GTTTATTGgC CCATTGGATA ACCGTGGGAA ATCTAGAGCT AATACATGCA GTTTATTGGC CCATTGGATA ACCGTGgGAA ATCTAGAgCT AAtACATGCA GTTTATTGgC CTATTGgAtA ACCGTGgGAA ATCTAgAgCT AAtACATGCA GCCAATGgtC

$$
\begin{aligned}
& \ldots|\ldots| \ldots|\ldots| \ldots|\ldots| \ldots|\ldots| \ldots \mid \\
& 120 \quad 130 \quad 140 \quad 150
\end{aligned}
$$

GTAGTCGCAA GgtTGCGTCA AAgCAtTtAT TAgACTTAAC CATCTACtAT GTGGCCGCAA GGTTGCGTCA AAGCATTTAT TAGACTTAAC CATCTACTAT GTAGTCGCAA GGTTGCGTCA AAGCATTTAT TAGACTTAAC CATCTACTAT GTAGTCGCAA GGTTGCGTCA AAGCATTTAT TAGACTTAAC CATCTACTAT GTTGCCGCAA GGTTGCGTCA AAGCATTTAT TAGACTTAAC CATCTACTAT GTTATCGCAA GGTGGCGTCA AAGCATTTAT TAGACTTAAC CATCTACTAT GGGCTTGCTC GG-----CC AAGCATTTAT TAGTTTTAAC CAATTACTGC

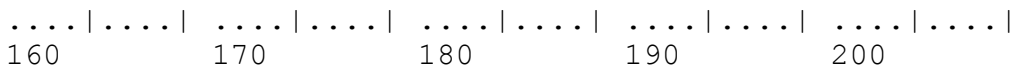

M. Blitar AtgtAAAgGC GAAtCtAgAt AACTTtgCtG AtCGCtAgtg CCGACGACGT FJ710800.1 ACGCAAAGGC GAATCTAGAT AACTTTGCTG ATCGCTCGTG CCGACGACGT FJ841887.1 ATGTAAAGGC GAATCTAGAT AACTTTGCTG ATCGCTAGTG CCGACGACGT KT240127.1 ATGTAAAGGC GAATCTAGAT AACTTTGCTG ATCGCTAGTG CCGACGACGT LC228235.1 ATGTAAAGGC GAATCTAGAT AACTTTGCTG ATCGCTAGTG CCGACGACGT LC228236.1 ATGTAAAGGC GAATCTAGAT AACTTTGCTG ATCGCTAGTG CCGACGACGT MH521300.1 GCAAGAAGGT GAATCTAGAT AACTTTGCTG ATCGTTAGTG TGCCAGCGAC

$\ldots|\ldots| \ldots|\ldots| \ldots|\ldots| \ldots|\ldots| \ldots|\ldots| \ldots|\ldots|$

$\begin{array}{llll}210 & 220 & 230 & 240\end{array}$

M. Blitar TTCAATTGA TTTCTGCCCT ATCAATTTGT TGGTAAGGTA TTGGCTTACC FJ710800.1 TTCAATTGA TTTCTGCCCT ATCAATTTGT TGGTAAGGTA TTGGCTTACC FJ841887.1 TTCAATTGAG TTTCTGCCCT ATCAATTTGT TGGTAAGGTA TTGGCTTACC KT240127.1 TTCAATTGA TTTCTGCCCT ATCAATTTGT TGGTAAGGTA TTGGCTTACC LC228235.1 TTCAATTGA TTTCTGCCCT ATCAATTTGT TGGTAAGGTA TTGGCTTACC LC228236.1 TTCAATTGA TTTCTGCCCT ATCAATTTGT TGGTAAGGTA TTGGCTTACC MH521300.1 GTTTCAATTG AGTTTCTGCC CTATCAATTG GTTGGTAAGG TTTTGGCTTA $\ldots|\ldots| \ldots|\ldots| \ldots|\ldots| \ldots|\ldots| \ldots|\ldots| \ldots|\ldots| \ldots \mid$

$260 \quad 270 \quad 280 \quad 290 \quad 300$

M. Blitar AAgGtTgCAA CGgGtAACGG GGAATCAGGG TTCGAtTCCG GAgAgGGAGC FJ710800.1 AAGGTTGCAA CGGGTAACGG GGAATCAGGG TTCGATTCCG GAGAGGGAGC FJ841887.1 AAgGTTGCAA CGGGTAACGG GGAATCAGGG TTCGATTCCG GAGAGGGAGC KT240127.1 AAgGTTGCAA CGgGTAACGG GGAATCAGGG TTCGATTCCG GAGAGGGAGC LC228235.1 AAGGTTGCAA CGGGTAACGG GGAATCAGGG TTCGATTCCG GAGAGGGAGC LC228236.1 AAgGTtGCAA CGGGTAACGG GGAATCAGGG TTCGATTCCG GAGAGGGAGC 


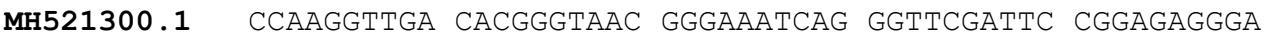

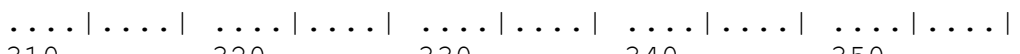

$\begin{array}{lllll}310 & 320 & 330 & 340 & \cdots\end{array}$

M. Blitar CTGAGAAACG GCTACCACAT CCAAGGAAGG CAGCAGGCGC GCAAATTACC FJ710800.1 CTGAGAAACG GCTACCACAT CCAAGGAAGG CAGCAGGCGC GCAAATTACC FJ841887.1 CTGAGAAACG GCTACCACAT CCAAGGAAGG CAGCAGGCGC GCAAATTACC KT240127.1 CTGAGAAACG GCTACCACAT CCAAGGAAGG CAGCAGGCGC GCAAATTACC LC228235.1 CTGAGAAACG GCTACCACAT CCAAGGAAGG CAGCAGGCGC GCAAATTACC LC228236.1 CTGAGAAACG GCTACCACAT CCAAGGAAGG CAGCAGGCGC GCAAATTACC MH521300.1 GCTTGAGAAT CGGACCACCA CATCCGAAGA AGGCAGCAGG CGCGCAAATT

$\ldots|\ldots| \ldots|\ldots| \ldots|\ldots| \ldots|\ldots| \ldots|\ldots| \ldots|\ldots| \ldots \mid$

$\begin{array}{lllll}360 & 370 & 380 & 390 & 400\end{array}$

M. Blitar CAATCTAGAC AgtAggAggt GgtgAagAgA AgtACtTAgt GgtgGcCAAA FJ710800.1 CAATCTAGAC AGTAGGAGGT GGTGAAGAGA AGTACTTAGT GGTGGCCTAA FJ841887.1 CAATCTAGAC AGTAGGAGGT GGTGAAGAGA AGTACTTAGT GGTGGCCAAA KT240127.1 CAATCTAGAC AGTAGGAGGT GGTGAAGAGA AGTACTTAGT GGTGGCCAAA LC228235.1 CAATCTAGAC AGTAGGAGGT GGTGAAGAGA AGTACTTAGT GGTGGCCTAA LC228236.1 CAATCTAGAC AGTAGGAGGT GGTGAAGAGA AGTACTTAGT GGTGGCCTAA MH521300.1

$\ldots . . . . \mid$

410 AAATCAATCT AGACAgTAGG AgGTGGTGAA GAGAAGTACT AAGTGGTTTA

M. Blitar

FJ710800.1 420 $\ldots+\cdots|\cdots|$

$4 \dot{50}$

FJ841887.1

KT240127.1

LC228235. 1

LC228236. 1

MH521300.1

$\ldots . \ldots|\ldots|$

460 420

TGGTCCCAAC TAGGAATGAA CGTAATTTAA GCAATTCGAT GAGTAACTAC TGGTCCCAAC TAGGAATGAA CGTAATTTAA GCAATTCGAT GAGTAACTAC TGGTCCCAAC TAGGAATGAA CGTAATTTAA GCAATTCGAT GAGTAACTAC TGGTCCCAAC TAGGAATGAA CGTAATTTAA GCAATTCGAT GAGTAACTAC TGGTCCCAAC TAGGAATGAA CGTAATTTAA GCAATTCGAT GAGTAACTAC TGGTCCCAAC TAGGAATGAA CGTAATTTAA GCAATTCGAT GAGTAACTAC TTTTTACCCC TAGCTTGGAA TGGACGTAAT TTAAGCAATT CGATGAGTAT

M. Blitar

FJ710800.1

FJ841887.1

KT240127.1

LC228235. 1

LC228236. 1

MH521300.1

$\ldots . \ldots . \mid$

510 $\ldots|\ldots| \ldots|\ldots| \ldots|\ldots| \ldots|\ldots| \ldots \mid$

470

480

500

TGGAGGGCAA GTCCTGGTGC CAGCAGCCGC GGTAATTCCA GCTCCAGTGG TGGAGGGCAA GTCCTGGTGC CAGCAGCCGC GGTAATTCCA GCTCCAGTGG TGGAGGGCAA GTCCTGGTGC CAGCAGCCGC GGTAATTCCA GCTCCAGTGG TGGAGGGCAA GTCCTGGTGC CAGCAGCCGC GGTAATTCCA GCTCCAGTGG TGGAGGGCAA GTCCTGGTGC CAGCAGCCGC GGTAATTCCA GCTCCAGTGG TGGAGGGCAA GTCCTGGTGC CAGCAGCCGC GGTAATTCCA GCTCCAGTGG CTACTGGAGG GCAAGTCCTG GTGCCAGCCC GGGGGTTAAT TCCAGCTCCA

M. Blitar

FJ710800.1 FJ841887.1 $\mathrm{KT} 240127.1$ LC228235. 1 LC228236. 1 MH521300.1 $\ldots \ldots|\ldots|$

560 $\ldots|\ldots| \ldots|\ldots| \ldots|\ldots| \ldots|\ldots| \ldots \mid$

$520 \quad 530 \quad 540 \quad 550$

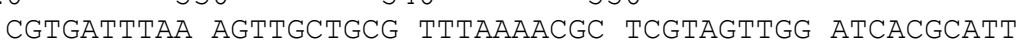
CGTGATTTAA AGTTGCTGCG TTTAAAACGC TCGTAGTTGG ATCACGCAGT CGTGATTTAA AgTTGCTGCG TTTAAAACGC TCGTAGTTGg ATCACGCAGT CGTGATTTAA AGTTGCTGCG TTTAAAACGC TCGTAGTTGg ATCACGCAgT CGTGATTTAA AGTTGCTGCG TTTAAAACGC TCGTAGTTGG ATCACGCAGT CGTGATTTAA AGTTGCTGCG TTTAAAACGC TCGTAGTTGG ATCACGCAGT GTGGCGTGAT TTAAAGTTGC TCGTATTAAA ACGCTCGTAG TTGGATCATG $\ldots|\ldots| \ldots|\ldots| \ldots|\ldots| \ldots|\ldots| \ldots \mid$

M. Blitar

FJ710800.1 FJ841887. 1 KT240127. 1 LC228235. 1 LC228236. 1 MH521300.1 $\ldots . \ldots \mid$

610

M. Blitar FJ710800.1 FJ841887.1 KT240127. 1 LC228235. 1 LC228236. 1
570 580

590

600

GGCATGTAGT AACACAAATT TGGTCGACTG ACGATTTTCT TTCTCAAGAT GGCATATAGT AACACAGATT TGGTCGAGTG ACGATTTTCT TTTCCGAGAT GGCATGTAGT AACACAAATT TGGTCGACTG ACGATTTTCT TTCTCAAGAT GGCATGTAGT AACACAAATT TGGTCGACTG ACGATTTTCT TTCTCAAGAT GGCATATAGT AACACAAATT TGGTCGAATG ACGATTTTCT TTCTCGAGAT GGCATATAGT AACACAAATT TGGTCGAATG ACGATTTTCT TTCTCGAGAT CGgTAACTGT TTGTAGTCTA TGgTCGACTG ACTAGCGAAC ATCTTTGGCT $\ldots|\ldots| \ldots|\ldots| \ldots|\ldots| \ldots|\ldots| \ldots \mid$

$620630 \quad 640 \quad 650$

TATTGAATCT TGACCGGTTT GTGTGTTAAC GCTATATGTC ACTATTTGCA TATTGGATCT TGACCTGTCT GTGTGTTCAC GCTATATGTC ACTATTTGCA TATTGAATCT TGACCGGTTT GTGTGTTAAC GCTATATGTC ACTATTTGCA TATTGAATCT TGACCGGTTT GTGTGTTAAC GCTATATGTC ACTATTTGCA TATTGGATCT TGACCGGTTT GTGTGTTCAC GCTATATGTC ACTATTTGCA TATTGGATCT TGACCGGTTT GTGTGTTCAC GCTATATGTC ACTATTTGCA 
MH521300.1 GATTCAGCTG ATGTTCGCAA GTGTAGATAA CAACGCAAAC TGTTACTATT $\ldots|\ldots| \ldots|\ldots| \ldots|\ldots| \ldots|\ldots| \ldots|\ldots| \ldots \mid$
660 670
680
690
$\ddot{700}$

M. Blitar CACAAGTATG ATATTTGGTC TGTAGTGAAT CGAGTATCGT GTCTTGTGGA

FJ710800.1 CACAAGTATG ATATTTGGTC TTTAGTGAAT CGAGTATCGT GTCTTGTGGA

FJ841887.1 CACAAGTATG ATATTTGGTC TTTAGTGAAT CGAGTATCGT GTCTTGTGGA

KT240127.1 CACAAGTATG ATATTTGGTC TTTAGTGAAT CGAGTATCGT GTCTTGTGGA

LC228235.1 CACAAGTATG AAATTTGGTC TTTAGTGAAT CGAGTTTCGT GTCTTGTGGA

LC228236.1 CACAAGTATG AAATTTGGTC TTTAGTGAAT CGAGTTTCGT GTCTTGTGGA

MH521300.1

TAATCGCAAG TATGTTGATT GACCTTTACT GAGTTGATGA TCATATTGTG

$\ldots . . . .1$

710 $\ldots|\ldots| \ldots|\ldots| \ldots|\ldots| \ldots|\ldots| \ldots \mid$

M. Blitar

FJ710800.1

720

730

740

750

FJ841887.1

KT240127.1

LC228235. 1

LC228236. 1

MH521300.1

$\ldots . \ldots . \mid$

GTGTGCCTTG AATAATACAA AGTGCTCCAA GCATGCGCAC GCTTGAATGT GTGTGCCTTG AATAAAACAG AGTGCTCAAA GCAGGCGAAC GCTTGAATGT GTGTGCCTTG AATAAAACAG AGTGCTCAAA GCAGGCGAAC GCTTGAATGT GTGTGCCTTG AATAAAACAG AGTGCTCAAA GCAGGCGAAC GCTTGAATGT GTGTGCCTTG AATAAAACAG AGTGCTCAAA GCAGGCGAAC GCTTGAATGT GTGTGCCTTG AATAAAACAG AGTGCTCAAA GCAGGCGAAC GCTTGAATGT CGGTTCGTGC CTTGAATAAA ACAGAGTGCT CAAAGCAGGC GCGTGCTTGA

760

M. Blitar

FJ710800.1

FJ841887. 1

KT240127.1

LC228235. 1

LC228236. 1

MH521300. 1

$\ldots . \ldots|\ldots|$

810

M. Blitar

FJ710800.1

FJ841887.1

KT240127. 1

LC228235. 1

LC228236. 1

MH521300.1

$\ldots|\ldots|$

860

M. Blitar

FJ710800.1

FJ841887.1

KT240127. 1

LC228235. 1

LC228236. 1

MH521300.1

$\ldots|\ldots|$

910

M. Blitar

FJ710800.1

FJ841887.1

KT240127. 1

LC228235. 1

LC228236. 1

MH521300.1

$\ldots|\ldots|$

960

M. Blitar

FJ710800.1

FJ841887. 1

KT240127. 1

LC228235. 1

LC228236. 1

MH521300.1

$$
\ldots|\ldots| \ldots|\ldots| \ldots|\ldots| \ldots|\ldots| \ldots \mid
$$

$$
770 \quad 780 \quad 890 \quad 800
$$

TAtAgCATGg AACGAACAAA CGTGTATTTG CGATATGTTG AgCACTTGAA tAtAgCAtgG AACGAACAAA CGTGTAtTtg CAtACGTtTg AAgAgttgGg TAtAGCATGg AACGAACAAA CGTGTATTTG CGTATGTTTG AGCAGTTGAg TATAGCATGG AACGAACAAA CGTGTATTTG CGTATGTTTG AGCAGTTGA TATAGCATGG AACGAACAAA CGTGTATTTG TGTATGTTTG AGCAGTTGA TATAGCATGG AACGAACAAA CGTGTATTTG CGTACGTTTA GGCAGTTGAG AtgtTgtagC AtgGAACGAA CAAACGTGtA TtCGCGTGCA TCGTGCGAGG $\ldots|\ldots| \ldots|\ldots| \ldots|\ldots| \ldots|\ldots| \ldots \mid$
820$$
830
$$
840
850

GCGCAACTTG ATTGCTTGA CGTACGCAGC ACGCGTCCAA ATACGGATGT GGCAACCTCG ATTTTTTGGA CGTATGCAGC ACCCGCCTAA ATACGGATGT GGCAACTTTG ATTGCTTGA CGTACGCAGC ACCCGCCAAA ATACGGATGT GGCAACTTTG ATTGCTTGA CGTACGCAGC ACCCGCCAAA ATACGGATGT GGCAACTTTG ACTGTTTGAG CGTATGCAGC ACCCGCCTAA ATACGGATGT GGCAACTTTG GCTGTTTGAG CGTACGCAGC ACCCGCCTAA ATACGGATGT TGAGTGTGCT TCGGTGCGTG TTGATGTATG CATCACCCGC CAAAATACGA $\ldots|\ldots| \ldots|\ldots| \ldots|\ldots| \ldots|\ldots| \ldots|\ldots|$

870 880

890 900

TGGTTGTCGT ATCAGGTGAT GGATtAACAg AgCAgtTAgG GGCATTGGTA TGGTTTTCGT ATCAGGTGAT GATTAACAGG AGCGGTTGGG GGCATTGGTA TGGTTTTCGT ATCAGGTGAT GATTAACAGG AGCGGTTGGG GGCATTGGTA TGGTTTTCGT ATCAGGTGAT GATTAMCAGG AGCGGTTGGG GGCATTGGTA TGGTTTTCGT ATCAGGTGAT GATTAACAGG AGCGGTTGGg GGCATTGGTA TGGTTTTCGT ATCAGGTGAT GATTAACAGG AGCGGTTGGG GGCATTGGTA TTGTTGGTTA GTCAATAAGG TGATGATTAA AAgGAGCGGT TGGGGGCATT $\ldots|\ldots| \ldots|\ldots| \ldots|\ldots| \ldots|\ldots| \ldots \mid$

920 930

940

950

TTTGGCCACG AGAGGTGAAA TTCTTGGACC GGCCAAGACT ACAGAAGCAA TTTGGCCGCG AGAGGTGAAA TTCTTGGACC GGCCAAGGAC TAACAGATAA TTTGGCCGCG AGAGGTGAAA TTCTTGGACC GGCCAAGGAC TAACAGATAA TTTGGCCGCG AGARGTGAAA TTCTTGGACC GGCCAAGGAC TAACAGATAA TTTGGCCGCG AGAGGTGAAA TTCTTGGACC GGCCAAGGAC TAACAGATAA TTTGGCCGCG AGAGGTGAAA TTCTTGGACC GGCCAAGGAC TAACAGATAA GGTATTTGGA CGCGAGAGGT GAAATTCAAA GACCGTCCAA GGACTAACTG $\ldots|\ldots| \ldots|\ldots| \ldots|\ldots| \ldots|\ldots|$

$970 \quad 980 \quad 990 \quad 1000$

AGCGTTGTCA GACCGTTCCA TTATCAgAAC AAAGTGGAGG TCGAAACATC GgCGTTTGTC TAGACCGTTT CCATtAATCA AgAACGAAAg TGGGAGGTTC GGCGTTTGTC TAGACCGTTT CCATTAATCA AgAACGAAAg TGGGAGGTTC GGCGTTTGKC TAGACCGTTT CCATTAATCA AGAACGAAAG TGGGAGGTTC GGCGTTTGTC TAGACCGTTT CCATTAATCA AgAACGAAAg TGGGAGGTTC GGCGTTTGTC TAGACCGTTT CCATTAATCA AgAACGAAAg TGGGAGGTTC CGAAgGCATC TGTCCAGACC GTATCCATTA ATCAAGAACG AAAGTGGGA $\ldots|\ldots| \ldots|\ldots| \ldots|\ldots| \ldots|\ldots| \ldots \mid$ 
Journal of Aquaculture Science

DOI: https://doi.org/10.31093/joas.v5i1.89
April 2020 vol 5 (1): 38-53

Online pada http://joas.co.id
1010
1020
1030
1040
1050
M. Blitar AATACGTCTA GTCCACAAAA CTTGCGACTG ATCGTTAGGA TACAAGCCAG FJ710800.1 GAAGACGATC AGATACCGTC CTAGTTCCCA CTATAAACTA TGCCGACCTG FJ841887.1 GAAGACGATC AGATACCGTC CTAGTTCCCA CTATAAACTA TGCCGACCTG KT240127.1 GAAGACGATC AGATACCGTC CTAGTTCCCA CTATAAACTA TGCCGACCTG LC228235.1 GAAGACGATC AGATACCGTC CTAGTTCCCA CTATAAACTA TGCCGACCTG LC228236.1 GAAGACGATC AGATACCGTC CTAGTTCCCA CTATAAACTA TGCCGACCTG MH521300.1 $\ldots . . \ldots \mid$
$1060 \quad 1070 \quad 1080 \cdots 10100$ GTTCGAAGAC GATTAGATAC CGTCGTAGTC CCAACCGTAA ACTATGCCGA
M. Blitar GTGGTCCCTG GAATCAGTTT CGTTCGGGAA GTTGTCCATT CTAACTAAGG FJ710800.1 GCAGTTTAGT GATTAACAAG CTCTAGGTTG GTCCCCCTGG GAAACCTCAA FJ841887.1 GCAGTTTAGT GATTAACAAG CTCTAGGTTG GTCCCCCTGG GAAACCTCAA KT240127.1 GCAGTTTAGT GATTAACAAG CTCTAGGTTG GTCCCCCTGG GAAACCTCAA LC228235.1 GCAGTTTAGT GATTAACAAG CTCTAGGTTG GTCCCCCTGG GAAACCTCAA LC228236.1 GCAGTTTAGT GATTAACAAG CTCTAGGTTG GTCCCCCTGG GAAACCTCAA MH521300.1 CGGATCAGCT TGGGATATTG CAAGCATCAA GTTGGTCTCC AAGGGAAACC $\ldots|\ldots| \ldots|\ldots| \ldots|\ldots| \ldots|\ldots| \ldots|\ldots| \ldots \mid$
1110
1120
1130
1140
1150 FJ710800.1 GTTTTTCGGT TACGGGGAGA GTATGGTCGC AAGTCTGAAA CTTAAAGGAA FJ841887.1 GTTTTTCGGT TACGGGGAGA GTATGGTCGC AAGTCTGAAA CTTAAAGGAA KT240127.1 GTTTTTCGGT TACGGGGAGA GTATGGTCGC AAGTCTGAAA CTTAAAGGAA LC228235.1 GTTTTTCGgT TACGGGGAGA GTATGGTCGC AAGTCTGAAA CTTAAAGGAA LC228236.1 GTTTTTCGGT TACGGGGAGA GTATGGTCGC AAGTCTGAAA CTTAAAGGAA MH521300.1 ATAAGTTTTT CGGTTACGGG GAGAGTATGG TCGCAAGTCT GAAATTTAAA $\ldots|\ldots| \ldots|\ldots| \ldots|\ldots| \ldots|\ldots| \ldots|\ldots| \ldots|\ldots|$
1160
1170
1180
1190
1200
M. Blitar TCAAGTAAAA CTAAACTTTT GACGGAgGgG GCGGCGTTAA TTGGGATGTG
FJ710800.1 FJ841887.1 $\mathrm{KT} 240127.1$ LC228235.1 LC228236. 1 MH521300.1 $\ldots+\ldots \mid$ 1210 TTGACGGAAG GGCACCACCA GGgGTGGAGC CTGCGGCTTA ATTTGACTCA TTGACGGAAG GGCACCACCA GGGGTGGAGC CTGCGGCTTA ATTTGACTCA TTGACGGAAG GGCACCACCA GGgGTGgAgC CTGCGGCTTA ATTTGACTCA TTGACGGAAG GGCACCACCA GGGGTGGAGC CTGCGGCTTA ATTTGACTCA TTGACGGAAG GGCACCACCA GGGGTGGAGC CTGCGGCTTA ATTTGACTCA GGAATTGACG GAAGGGCACC ACCAGGGGTG GAACCTGCGG CTTAATTTGA
M. Blitar $\ldots|\ldots| \ldots|\ldots| \ldots|\ldots| \ldots|\ldots|$ 122 1230 1240 1250
FJ841887.1 KT240127.1 LC228235. 1 GTATCGTAAA AACCCTTCTT AAAAAAAGAg GTTAGTTCCG GTGAATCCCC ACACGGGGAA ACTTACCTGG TCCGGACATC GAAAGGATAG ACAGACTGAT ACACGGGGAA ACTTACCTGG TCCGGACATC GAAAGGATAG ACAGACTGAT ACACGGGGAA ACTTACCTGG TCCGGACATC GAAAGGATAG ACAGACTGAT ACACGGGGAA ACTTACCTGG TCCGGACATC GAAAGGATAG ACAGACTGAT ACACGGGGAA ACTTACCTGG TCCGGACATC GAAAGGATAG ACAGACTGAT

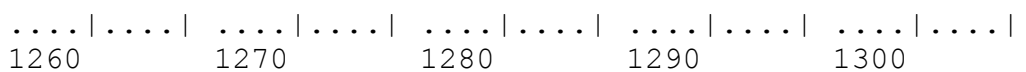

M. Blitar AAgTGTtTAT TGgGgGgGCC CTTGgTtTCA GAATGCTGTT GGTAGTCCCT FJ710800.1 AGATCTTTCT TGATGCGGTG AGTGGTGGTG CATGGCCGTT CTTAGTTCGT FJ841887.1 AGATCTTTCT TGATGCGGTG AGTGGTGGTG CATGGCCGTT CTTAGTTCGT KT240127.1 AGATCTTTCT TGATGCGGTG AGTGGTGGTG CATGGCCGTT CTTAGTTCGT LC228235.1 AGATCTTTCT TGATGCGGTG AGTGGTGGTG CATGGCCGTT CTTAGTTCGT LC228236.1 AGATCTTTCT TGATGCGGTG AGTGGTGGTG CATGGCCGTT CTTAGTTCGT MH521300.1 TGATAGATCT TTTTTGATGC GGTGAGTGGT GGTGCATGGC CGTTCCTAGT $\ldots|\ldots| \ldots|\ldots| \ldots|\ldots| \ldots|\ldots| \ldots|\ldots| \ldots \mid$
1310
1320
1330
1340 1350

M. Blitar FJ710800.1 FJ841887.1 $\mathrm{KT} 240127.1$ LC228235. 1 LC228236. 1 MH521300.1 $\ldots|\ldots| \ldots|\ldots| \ldots|\ldots| \ldots|\ldots| \ldots \mid$
GCAAGAATAA GTCGAATCCT CTTCGATACC AAAAGGTCAT TGGTTTTTTC GGAGTGATCT GTCAGGTTTA TTCCGGTAAC GAACGAGACC ACCTTCTCCA GGAGTGATCT GTCAGGTTTA TTCCGGTAAC GAACGAGACC ACCTTCTCCA GGAGTGATCT GTCAGGTTTA TTCCGGTAAC GAACGAGACC ACCTTCTCCA GGAGTGATCT GTCAGGTTTA TTCCGGTAAC GAACGAGACC ACCTTCTCCA GGAGTGATCT GTCAGGTTTA TTCCGGTAAC GAACGAGACC ACCTTCTCCA TCGTGGAGTG ATCTGTCAGG TTGATTCCGg TAACGAACGA GACTACAACC 


$\begin{array}{lrlll}\text { 1360 } & 1370 & 1380 & 1390 \\ \text { M. Blitar } & \text { ATTTCCATAT } & \text { TCTTTTACAT } & \text { GATAGGAAGT } & \text { AGCGTAGGTT } \\ \text { FJ710800.1 } & \text { TTTAAGAAAC } & \text { AGTAGTAGGA } & \text { GGCTGGTTGT } & \text { TGCTTCGGTG } \\ \text { FJ841887.1 } & \text { TTTAAGAAAC } & \text { AGTAGCAGGA } & \text { GGTTGGATGT } & \text { TGCTTCGGTG } \\ \text { KT240127.1 } & \text { TTTAAGAAAC } & \text { AGTAGCAGGA } & \text { GGTTGATGT } & \text { TGCTTCGGTG } \\ \text { LC228235.1 } & \text { TTTAAGAAAC } & \text { AGTAGCAGGA } & \text { GGCTGGTTGT } & \text { TGCTTCGGTG } \\ \text { LC228236.1 } & \text { TTTAAGAAAC } & \text { AGTAGCAGGA } & \text { GGCTGGATGT } & \text { TGCTTCGGT } \\ \text { MH521300.1 } & \text { TTCATTTAAG } & \text { AGGCAAAAGC } & \text { AGGAGGGCGA } & \text { AAGGCATTTC }\end{array}$

Hasil sequensing DNA parasit Myxobolus koi yang menginfeksi ikan koi (Cyprinus carpio) di Blitar memiliki kemiripan (percent identity) dari data Gen Bank dengan beberapa organisme. (Tabel 4). Kemiripan atau tingkat homologi dari sampel antara 95,99 - 99,37\% dengan E-value 0.0, kemiripan tertinggi terjadi pada kode sampel KT.240127.1 yaitu pada Myxobolus koi yang menginfeksi ikan Rainbow trout (Oncorhynchus mykiss) di Barat Daya China, kemiripan dikatakan tinggi apabila sekuen DNA memiliki nilai percen identity $>70 \%$ dan $E$ value $<10^{-4} \quad$ (Claverie dan Notredame, 2003). Analisis filogenetik dengan menggunakan program komputer ClustalW dengan boostrap 1000 kali, terhadap susunan basa nukleotida utamanya sekuen sampel Myxobolus koi bertujuan untuk membandingkan hubungan kekerabatan antara sampel dengan isolat pembanding. Isolat Myxobolus koi dari GenBank dapat digunakan sebagai acuan atau referensi untuk analisa terkait dengan data genomic dari suatu isolat yang ada sehingga dapat diperkirakan kecepatan evolusi yang terjadi dan dapat direkonstruksi hubungan evolusi antara satu organisme dengan yang lain. Hasil analisa philogenetik dapat dilihat pada Gambar 3 berikut ini.

Metode neighbor joining dengan software Mega 6.06 (Tamura et al., 2013) digunakan untuk membandingkan isolate parasit Myxobolus koi dari benih ikan koi (Cyprinus carpio) dengan 6 isolat pembanding (Tabel 4). Jarak genetik sampel Myxobolus koi dapat dilihat pada Tabel 5, Nilai jarak genetik ke 7 jenis Myxobolus berkisar antara 0,273 hingga 1,416. Nilai jarak tertinggi $(1,416)$ terdapat pada Myxobolus kingchowensis kode sampel MH.521300, sedangkan terdekat $(0,273)$ pada sampel Myxobolus koi pada ikan koi (Cyprinus carpio) kode sampel FJ841887.1 dan Myxobolus koi pada 
ikan rainbow trout (Oncorhynchus mykiss) kode sampel KT240127.1.

\section{KESIMPULAN}

Spora Myxobolus yang diperoleh dari Kabupaten Blitar memiliki ukuran panjang spora 11$14 \mu \mathrm{m}$ dengan rata-rata $12,82 \pm 0,75$ $\mu \mathrm{m}$ dan lebar 7-8 $\mu \mathrm{m}$ dengan ratarata $7,09 \pm 0,84 \mu \mathrm{m}$, sedangkan ukuran kapsul memiliki panjang 7-8 $\mu \mathrm{m}$ dengan rata-rata $7,36 \pm 0,497 \mu \mathrm{m}$ dan lebar 2-3 $\mu \mathrm{m}$ dengan rata-rata 2,64 $\pm 0,49 \mu \mathrm{m} \quad \mathrm{n}=10 . \quad$ Hasil elektroforesis ikan yang secara klinis terinfeksi Myxobolus koi muncul pita (band) pada 2000 bp. Hasil sequensing DNA parasit Myxobolus koi yang menginfeksi ikan koi (Cyprinus carpio) di Blitar memiliki kemiripan (percent identity) tertinggi dengan kode sampel KT.240127.1 yaitu pada Myxobolus koi yang menginfeksi ikan Rainbow trout (Oncorhynchus mykiss) di Barat Daya China. Jarak genetik sampel Myxobolus koi blitar terdekat pada sampel Myxobolus koi pada ikan koi (Cyprinus carpio) dengan kode sampel FJ841887.1 dan Myxobolus koi pada ikan rainbow trout (Oncorhynchus mykiss) dengan kode sampel KT240127.1. pada nilai yang sama 0,273 .

\section{DAFTAR PUSTAKA}

Alvin C. dan Matt J. Griffin, 2010. Molecular Characterization and Histopathology of Myxobolus koi Infecting the Gill of a Koi, Cyprinus carpio, with an Amende Morphological Description of the Agent. Journal of Parasitology. 96 (1): 116-124.

Camus., A.C, Jennifer A. Dill, Thomas G. Rosser, Linda M. Pote, Matt J. Griffin. 2017. Myxobolus axelrodi n. sp. (Myxosporea : Myxobolidae) a Parasite Infecting The Brain and Retinas of The Cardinal Tetra Paracheirodon axelrodi (Teleostei: Characidae). Parasitology Research. 116 (1) : 387-397.

Claverie, J., Notredame, C. 2003. Bioinformatics for Dummies, Wiley Publishing Inc, New York.

Fahmi M.R., Ruby Vidia Kusumah, Idil Ardi, Shofihar Sinansari, Eni Kusrini. 2017. DNA Barcoding Ikan Hias Introduksi. Jurnal Riset Akuakultur, 12 (1) : 29-40.

Fan,W., 2015. Mortality Associated with Infectious Haematopoietic Necrosis in Farmed Adult Rainbow Trout (Oncorhynchus mykiss) at Southwest China. Unpublished. Submitted (02Jul-2015)

Sichuan Aquaculture, University.
Agriculture 
Felsenstein, Joseph. 1985. Confidence Limits on Phylogenies: An Approach Using the Bootstrap. Evolution, 39 (4) : 783-791.

Fiala I., Pavla Bartošová-Sojková, Christopher M. Whipps. 2015. Classification and Phylogenetics of Myxozoa

Gunanti Mahasri. 2017. Development of Spore Protein of Myxobolus koi as an Immunostimulant for Prevent of Myxobolusis on Gold Fish (Cyprinus carpio Linn) by Oral Immunisation. IOP Conf. Ser.: Earth Environ.

Hofmaan, G.L. 1999. Parasites of North American Freshwater Fishes. Cornell University Press. New York. pp. 21-66

Kato,E., Kasai,A., Tomochi,H., Li,Y.C., Sato, H. 2017. Four Myxobolus spp. (Myxosporea: Bivalvulida) from the gill lamellae of common carp (Cyprinus carpio) and Japanese silver crucian carp (Carassius angsdorfii) in the western part of Japan, with the description of three new species (M. tanakai n. sp., $M$. paratoyamai n. sp., and $M$. ginbuna n. sp.). Parasitology Research. In press.

Kimura, M. 1980. A Simple Method for Estimating Evolutionary Rates of Base Substitutions Through Comparative Studies of Nucleotide Sequences. Journal of Molecular Evolution. 16:116-120.

Lokapirnasari, W.P., Adriana Monica Sahidu, Tri Nurhajati, Koesnoto Supranianondo, Andreas Berny Yulianto. 2017.
Sekuensing 16S DNA Bakteri Selulolitik Asal Limbah Cairan Rumen Sapi Peranakan Ongole. Jurnal Veteriner, 18(1); $76-82$.

Lom J, Dyková I. 1992. Protozoan parasites of fishes. Elsevier Science Publishers, New York

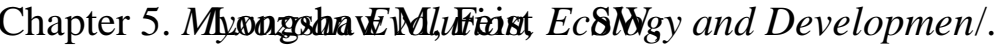
Canning EU, Okamura

Mathews, Patrick D., Omar Mertins, José O.L. Pereira, Antonio A.M. Maia, dan Edson A. Adriano. 2018. Morphology dan 18S RDNA Sequencing of Henneguya peruviensis $\mathrm{n}$. Sp. (Cnidaria: Myxosporea), a

Nurekawati, A.D, Gunanti Mahasri dan Muchammad Yunus. 2016. Identifikasi Myxobolus sp. pada Famili Cyprinidae Dengan Metode Molekuler di Provinsi Jawa Timur Dan Jawa Tengah. Jurnal Biosains. Vol $18,(2)$.

Robert, R.J. 2012. Fish Pathology Fourth Edition. Blackwell Publishing Ltd.

Sarjito, Slamet Budi Prayitno, Alfabetian Harjuno Condro Haditomo. 2013. Buku Pengantar Parasit dan Penyakit Ikan. Fakultas Perikanan Dan Ilmu Kelautan Universitas Diponegoro

Sugiyono. 2012. Metode Penelitian Kuantitatif Kualitatif dan R\&D. Alfabeta. Bandung.

Sumuduni, B.G.D., D.H.N. Munasinghea, A. Arulkanthan. 2018. Chronological Analysis of The Damages Caused by The Metacercariae Of Centrocestus formosanus in The Gills of Cyprinus carpio 
and Lesions Caused by The Adult Flukes In Ardeola ralloides : An experimental study. International Journal of Veterinary Science and Medicine, 6 (2): 165-171

Saitou, Naruya, and Masatoshi Nei. 1987. The Neighbor-Joining Method: A New Method for Reconstructing Phylogenetic Trees. Molecular biology and evolution, 4(4): 406-25.

Tamura, Koichiro et al. 2013. MEGA6 : Molecular Evolutionary Genetics Analysis Version 6.0. Molecular biology and evolution. 30(12): 2725 - 2729.

Tonguthai., K. 1997. Control of Freshwater Fish Parasits: a Southeast Asian Perspective. International Journal for Parasitology, Vol. 21. (10): 1185 - 1191.

Toha AHA, Widodo N, Hakim L, Sumitro SB. 2016. Panduan Dasar Analisis Data Genetik untuk Publikasi. Proyek Marine Biodiversity of Raja Ampat Islands. Kerjasama Universitas Papua-Universitas Brawijaya. $58 \mathrm{~h}$.

Wang, T., Bird, S., Zou, J., Secombes, C.J. 2018. Sequencing, Gene Organisation and Differential expression of two goldfish IL-1 beta genes. Journal Unpublished.

Yokoyama, H., Daisuke Inoue, Atsuro Kumamaru, Hisatsugu Wakabayashi. 1997. Myxobolus koi (Myxozoa: Myxosporea) Forms Large-and Small-Type 'Cysts' in the Gills of Common Carp. Fish Pathology, 32 (4): 211-217.

Zhang, J.Y., Yokoyama, H., Wang, J.G., Li, A.H., Gong,X.N., Ryu-Hasegawa,A., Iwashita,M. Ogawa, K. 2010. Utilization of Tissue Habitats by Myxobolus wulii Landsberg \& Lom, 1991 in different carp hosts and disease resistance in allogynogenetic gibel carp: redescription of $M$. wulii from China and Japan. Journal of Fish Diseases, 33(1): 57-68. 